\title{
Interleukin-6 Perpetrator of the COVID-19 Cytokine Storm
}

\author{
Jyoti Shekhawat $^{1}$ (i) Kavya Gauba $^{1}$ (i) $\cdot$ Shruti Gupta $^{1}$ (i) $\cdot$ Purvi Purohit $^{1} \cdot$ \\ Prasenjit Mitra $^{1} \cdot$ Mahendra Garg $^{2} \cdot$ Sanjeev Misra ${ }^{3}$ - Praveen Sharma ${ }^{1}$. \\ Mithu Banerjee ${ }^{1}[$ (B)
}

Received: 19 January 2021/Accepted: 8 June 2021/Published online: 21 June 2021

(C) Association of Clinical Biochemists of India 2021

\begin{abstract}
COVID-19 has emerged as a global pandemic. It is mainly manifested as pneumonia which may deteriorate into severe respiratory failure. The major hallmark of the disease is the systemic inflammatory immune response characterized by Cytokine Storm (CS). CS is marked by elevated levels of inflammatory cytokines, mainly interleukin-6 (IL-6), IL-8, IL-10, tumour necrosis factor- $\alpha$ (TNF- $\alpha$ ) and interferon- $\gamma$ (IFN- $\gamma$ ). Of these, IL-6 is found to be significantly associated with higher mortality. IL-6 is
\end{abstract}

Mithu Banerjee

mithu.banerjee.3@gmail.com

Jyoti Shekhawat

jyotikanwar1000@gmail.com

Kavya Gauba

kavyagauba17@gmail.com

Shruti Gupta

drshrutiga@gmail.com

Purvi Purohit

dr.purvipurohit@gmail.com

Prasenjit Mitra

prasy4u@gmail.com

Mahendra Garg

mkgargs@gmail.com

Sanjeev Misra

misralko@gmail.com

Praveen Sharma

praveensharma55@gmail.com

1 Department of Biochemistry, All India Institute of Medical Sciences, Jodhpur 342005, India

2 Department of Endocrinology, All India Institute of Medical Sciences, Jodhpur 342005, India

3 Department of Surgical Oncology, All India Institute of Medical Sciences, Jodhpur 342005, India also a robust marker for predicting disease prognosis and deterioration of clinical profile. In this review, the pivotal role played by IL- 6 in the immuno-pathology of COVID19 has been illustrated. The role of IL-6 as a pleiotropic cytokine executing both pro and anti-inflammatory activities has been reviewed. ADAM 10, a metalloproteinase switches the anti-inflammatory pathway of IL-6 to pro inflammatory hence blocking the action of ADAM 10 could be a new therapeutic strategy to mitigate the proinflammatory action of IL-6. Furthermore, we explore the role of anti-IL6 agents, IL-6 receptor antibodies which were being used for autoimmune diseases but now are being repurposed for the therapy of COVID- 19 .

Keywords Interleukin-6 · SARS-CoV-2 · Cytokine storm • ACE2 Receptor $\cdot$ Monoclonal antibodies

\section{Introduction}

Coronavirus Disease 2019 (COVID-19) was first reported in Wuhan, China, as a cluster of pneumonia cases with unknown etiology [1]. Since then, it has emerged as an outbreak and caused global havoc. On 30th January 2020, the disease had been declared as a Public Health Emergency of International Concern (PHEIC) by the World Health Organization (WHO) [2]. The etiological agent of the disease was soon identified as a member of the coronavirus family called Severe Acute Respiratory Syndrome Coronavirus 2 (SARS-CoV-2). Preceding the COVID-19 pandemic, two other outbreaks were witnessed in the twenty-first century, namely the Severe Acute Respiratory Syndrome (SARS) and the Middle East Respiratory Syndrome (MERS) caused by different pathogenic members of the coronavirus family (SARS-CoV and MERS-CoV) [3]. 
The immune pathogenesis, genome sequences and evolutionary phylogenetic relationship of SARS-CoV-2 with other coronaviruses have been fully elucidated [4]. The mortality rate of COVID-19 infection is $6.7 \%$ which is comparatively lower than for both SARS (10\%) and MERS (35\%) [5]. The disease presents itself similar to common flu with symptoms including fever, cough, nausea, headache, myalgia, dyspnea, pneumonia etc., some are asymptomatic while others may experience ARDS (actute respiratory distress syndrome) [6]. However, individuals with co-morbidities such as diabetes, hypertension or old age may experience exacerbated symptoms [7]. Interleukin-6 is a multifactorial cytokine which plays role in both pro-inflammatory pathways as well as anti-inflammatory pathways. In COVID-19 it has been reported to be elevated in from mild to critically ill patients. It is also correlated with disease patheogenesis and its progression [8].

\section{COVID-19 Pathogenesis}

The transmission of SARS-CoV-2 is primarily via aerosol droplets or contact with an infected person. Upon entry of the viral particle inside the lungs, it attaches itself to cells of the respiratory tract after which it is endocytosed into the host pulmonary cell. The crystallised structure of SARSCoV-2 shows the presence of surface spike (S) proteins, similar to those found in SARS-CoV, which binds to the Angiotensin-converting enzyme-2 (ACE-2) receptor present on the alveolar epithelial cells and it is responsible for conversion of Ang-II (angiotensin-II) to angiotensin 1-7 (Ang 1-7) in the renin angiotensin system [9]. The ACE2 receptor is crucial for the virulence of the virus as cells lacking them are found to be resistant to infection by SARS-CoV-2 infection [10]. ACE2 are not only expressed in both upper and lower respiratory tract but also in cell of small intestine, pancreas, kidneys, heart, oesophagus, bladder and brain making them all vulnerable to infection by SARS-CoV-2 [11]. It is noteworthy that normal ACE2 expression is not very high in upper respiratory tract and is only transiently enhanced in response to infection with SARS-CoV-2 for increased transmissibility of the virus [12]. Also, ACE2 expression in other tissues explains the development of multi-organ failure that often accompanies severe COVID-19 infection [13, 14]. After viral entry, spike protein is cleaved by transmembrane serine protease 2 (TMPRSS2) and then released by another protease called Furin, thus promoting viral entry through endosomal pathway as depicted in Fig. 1 [15]. The spike fusion peptide released by Furin then executes the virus-cell fusion contributing to viral spread and persistence. The low $\mathrm{pH}$ of the endosomal vesicle favours the delivery of viral genome into the cytoplasm allowing it to replicate and assemble into virions which are then released from the cell [16]. The infected cells are then subjected to apoptosis or necrosis, triggering an inflammatory response which is characterised by production of pro-inflammatory cytokines and simultaneous recruitment of macrophages and Th cells. Th1 $(\mathrm{CD} 4+)$ cells regulate antigen presentation and Interferon$\gamma$ production while Th17 cells induce secretion of IL-17, IL-21 and IL-22. This leads to further recruitment of other inflammatory cells such as neutrophils and CD8 cells [17]. Spread of infection into circulating immune cells causing their apoptosis, results in lymphocytopenia. A reduction in the total number of $\mathrm{T}$ cells results in a hyperinflammatory state in the body due to over secretion of cytokines and chemokines, termed as CS. CS, if untreated, may aggravated to other life-threatening scenarios such as Acute Respiratory Distress Syndrome (ARDS), Macrophage Activation Syndrome (MAS) and Secondary Hemophagocytic Lymphohistiocytosis (sHLH).

\section{Cytokine Storm Associated with SARS-CoV-2 Infection}

Hyper-cytokinemia or "Cytokine storm (CS)" in COVID19 is marked by an aggressive hyperinflammatory immune response and is the major hallmark of the disease [18]. It is a conglomeration of inflammatory symptoms induced by the activation of T-cells, macrophages and subsequent release of cytokines, which further potentiates recruitment and activation of other immune cells [19]. It is hypothesised that immune responses associated with MAS/HLH might be the driving force for COVID-19 related CS (20). CS is characterised by elevated serum levels of pro-inflammatory cytokines and chemokines, namely, IL-1, IL-6, IL-12, IFN- $\gamma$ and TNF- $\alpha[8,20,21]$. Elevated levels of these pro-inflammatory cytokines in severe patients might be useful as biomarkers of the disease prognosis and can be used as potential targets for therapy [22]. Several studies have suggested that CS, directly or indirectly, correlates with lung injury, ARDS, multi-organ failure, need for mechanical ventilation and unfavourable disease prognosis in COVID-19 [22, 23].

Along with cytokines, elevated levels of serum creatinine, lactate dehydrogenase, C-reactive protein, procalcitonin, ferritin, D-dimer and White Blood Cell count are the lab parameters that portend impending respiratory failure and need for supplementary oxygen in COVID-19 patients [23].

Of all the cytokines mediating the CS, IL- 6 has been proposed as the most accurate predictor of disease course as well as mortality in SARS-CoV-2 infected patients. Moreover, therapeutic implications targeting IL-6 or its 


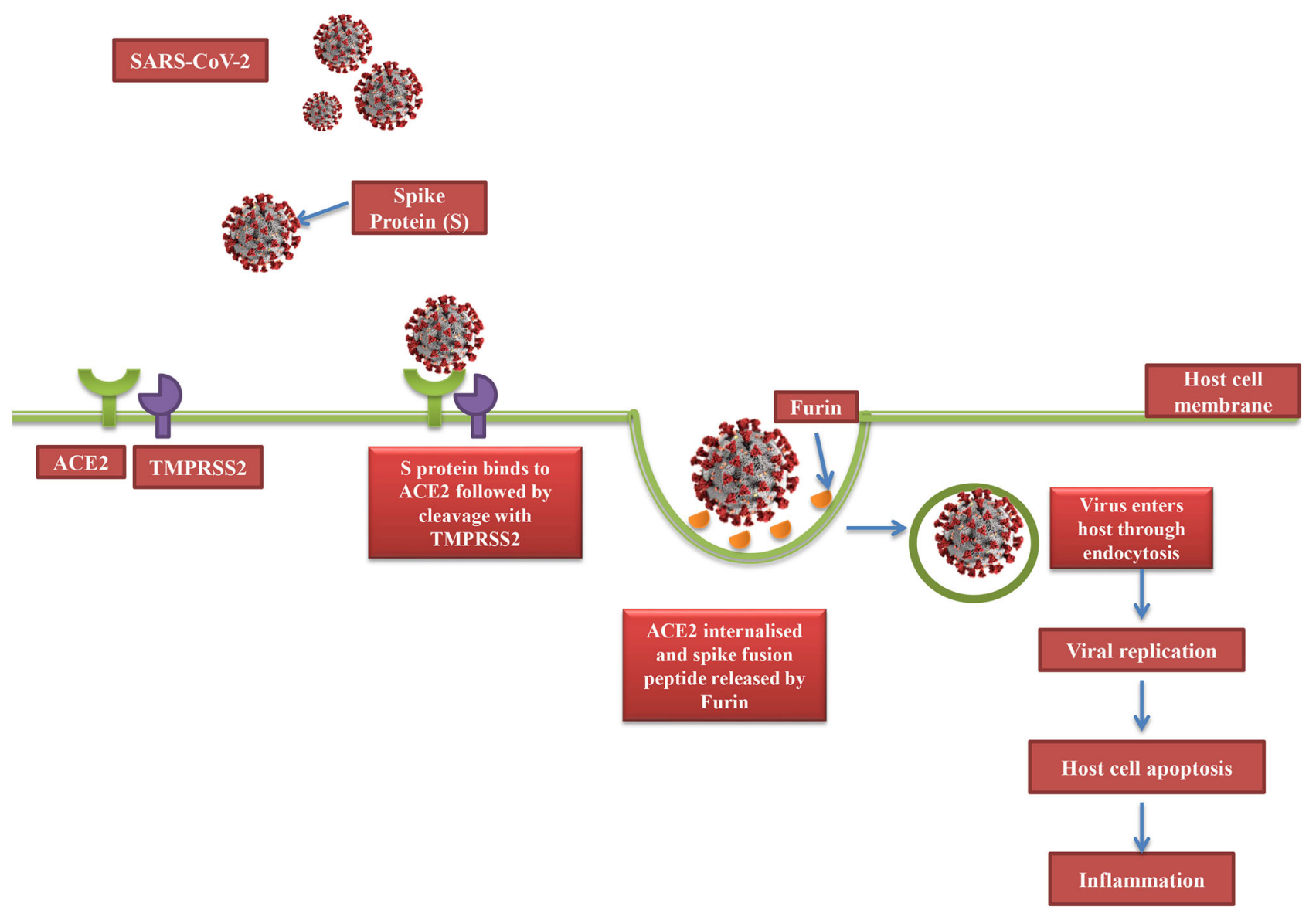

Fig. 1 SARS-CoV-2 entry into target cell. The virus binds to ACE2 receptor followed by cleavage of spike protein by a serine protease, TRMPSS2. This cleavage triggers the internalization of the virion

signalling have shown success in treatment of COVID-19 patients.

\section{IL-6 in Viral Immunity: A Double-Edged Sword}

Interleukin-6 is a pleiotropic cytokine produced in response to tissue damage by viral infections. The IL-6 signaling cascade is a highly regulated and dynamic process with well-defined pro and anti-inflammatory effects mediated by the Trans and Classical signal transduction respectively [24]. IL-6 homeostasis governs the outcomes of immunoprotection versus immunopathology of viral infections.

As a part of pro-inflammatory functions, Th17 activation and differentiation are dependent on IL-6. Rapid induction of granzyme B and perforin expression in $\mathrm{CD}^{+} \mathrm{T}$ cells which eliminates the viral pathogen is also dependant on IL-6 trans-signalling along with IL-15 [25]. The activation of these Cytotoxic T Lymphocytes (CTLs) then stimulates the release of $\mathrm{TNF}-\alpha$ and IFN- $\gamma$ which modulates particle through endocytosis. Then another protease called Furin acts to release the spike fusion peptide facilitating viral entry into host.s

neutrophil migration [26]. Furthermore, IL-6 serves as an endogenous pyrogenic cytokine serving as a thermoregulator and amplifying the immune surveillance in viral infections [27]. Early IL-6 signalling is known to promote IL-27 dependant maturation of regulatory $\mathrm{T}$ cells in lungs and limit viral immunopathology. Removal of either IL-6 or IL-27 is known to enhance viral infection. During respiratory viral infections, IL-6 acts as a driver of virusinduced immunopathology by inducing the production of IL-27 by monocytes and macrophages in the respiratory tract, promoting the local maturation of $\mathrm{T}$ cells [28]. Studies on IL-6 deficient mice infected with H1N1 influenza virus have shown that IL-6 is required to heal acute lung injury caused by influenza A virus [29]. Mice lacking IL-6 displayed reduced ability to mount an anti-viral immune response which was further associated with enhanced proliferation and migration of lung fibroblasts. These mice exhibited a compromised recruitment of macrophages in the lungs leading to reduced phagocytosis of viruses in lung macrophages [30]. 
On the other hand, as part of anti-inflammatory functions, IL-6 is involved in the progression of viral diseases, ultimately favouring viral persistence in infected hosts. IL6 promotes Th 2 response while inhibiting Th1 cell proliferation [31]. It does so by two mechanisms: Firstly, by stimulating CD4 $+\mathrm{T}$ cells to secrete IL-4 thus directing response to Th2 and secondly, by suppressing IFN- $\gamma$ expression by $\mathrm{CD} 4+\mathrm{T}$ cells which normally promotes Th1 polarization and is essential for an effective antiviral response [32]. IL-6 promotes Th17 cell differentiation leading to the production of IL-17 which upregulates the expression of anti-apoptotic molecules enhancing the survival of the virus in infected cells. IL-17 also blocks the destruction of target cells by CTLs. Neutralization of IL-17 augments virus clearance and enhances lysis by CTLs leading to elimination of virus-infected cells [33]. IL-17 also promotes migration of neutrophils to the lungs leading to tissue damage during inflammation (35). This infiltration by neutrophils leads to the development of Neutrophil Extracellular Traps (NETs) in the lungs which contributes to organ damage and COVID-19 related ARDS [34]. IL-6 produced by TLR-mediated signalling counter-regulates the $\mathrm{CD} 8+\mathrm{T}$ cell responses leading to $\mathrm{T}$-cell dysfunction in chronic viral infections [35]. It works synergistically with IL-1 $\beta$ and TNF $\alpha$ to induce trypsin upregulation in influenza virus-cytokine-trypsin cycle and this helps virus to replicate by activating matrix metalloproteinases that causes degradation of extracellular matrix. This IL-6 mediated trypsin upregulation may account for multi-organ failure in influenza virus infection [36].

IL-6 binds to its membrane-bound receptor to initiate the classic-type signalling which adds to anti-inflammatory processes as illustrated in Fig. 2. Cells lacking expression of membrane-bound IL-6 receptors are part of trans-signalling, mediated by soluble type receptor of IL-6 (sIL-6R) and gp130, responsible for pro-inflammatory functions of IL-6 [38]. sIL-6R is generated by the action of metalloproteinases known as ADAM10 and ADAM17 and alternative splicing mechanism [37]. Thus, therapeutic approaches need to be designed in a way that would attenuate the pro-inflammatory response without affecting the classic (anti-inflammatory) signalling process of IL-6 [38, 39]. Since ADAM10 plays a key role in switching from the classical (anti-inflammatory) to trans signalling pathway (pro-inflammatory), strategies to block its action holds a lot of promise in preventing the cytokine storm [37]. A fusion protein Sgp130-Fc has been developed from the conjugation of sgp130, a natural inhibitor of trans signalling cascade, and $\mathrm{Fc}$ region of $\mathrm{IgG}$ human antibody [40, 41]. This molecule specifically blocks trans signalling without effecting classic signalling pathway [42].

Therefore, the debatable role of IL- 6 as an anti- and proinflammatory cytokine requires vigilant evaluation for it to be considered as an effective therapeutic target in SARSCoV-2 infection.
Fig. 2 The classic and the trans-signalling pathways are mediated by the membranebound form of IL-6 receptor (mIL6R) and soluble form of IL-6 receptor (sIL6-R) respectively. Monoclonal antibodies against IL- 6 and IL6R can inhibit these pathways. Similarly, Janus Kinase Inhibitors (JAKinibs) inhibit phosphorylation of STAT (a transcription factor), thus blocking the downstream signalling of IL-6. ADAM10 plays a key role in switching from the classical to trans signalling pathway by converting sIL-6R to mIL-6R

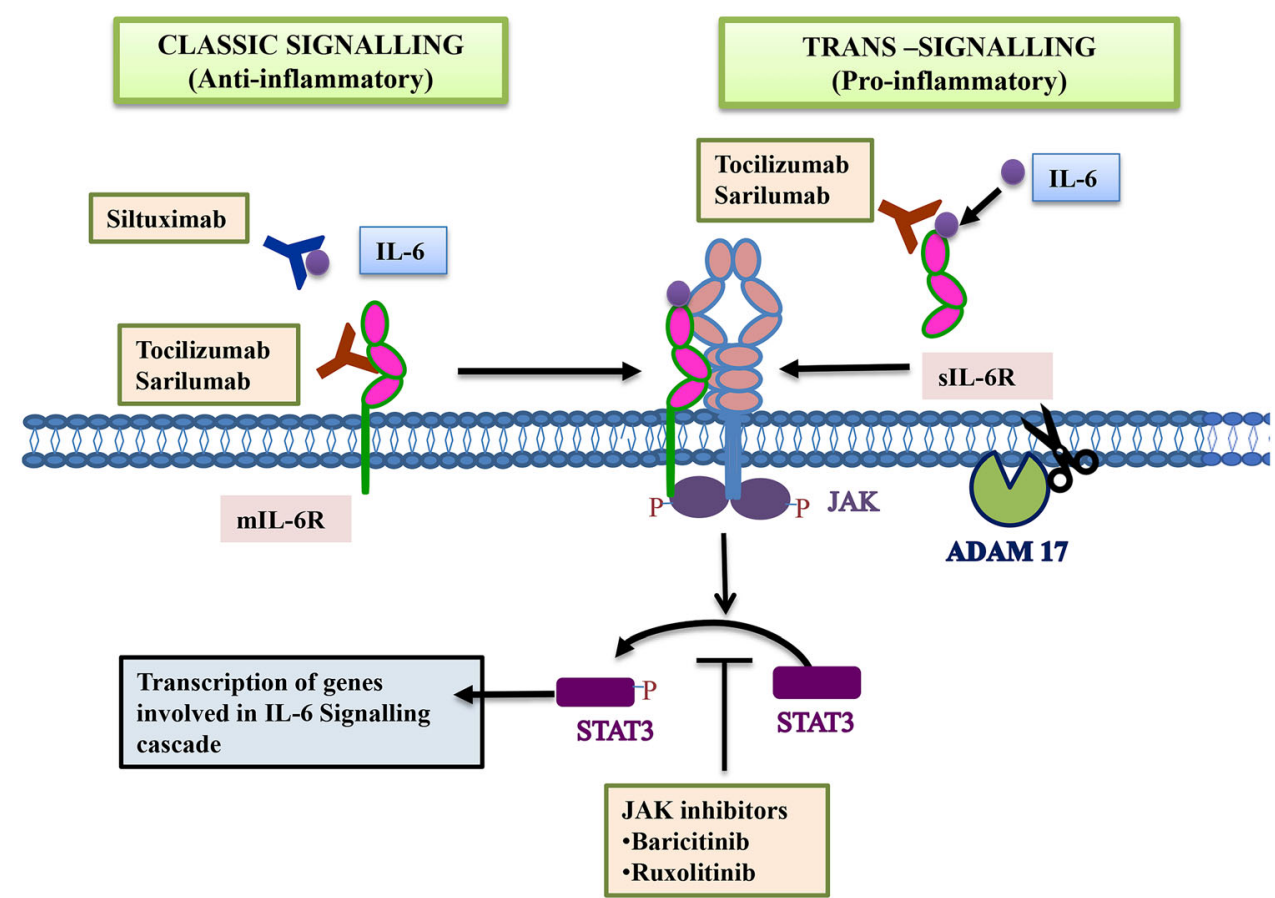




\section{IL-6: The Sidekick to ACE -2 Immunopathology in SARS-CoV-2 Infection}

There is evidence that suggests a strong association between circulating IL-6 levels and blood pressure. An increased IL-6 expression directly correlates with hypertension [43]. Therefore, hypertensive patients with COVID-19 who have elevated levels of IL-6 are highly susceptible to severe respiratory failure [44]. The ReninAngiotenstin Aldosterone System (RAAS) maintains the blood pressure and electrolyte balance by two major mechanisms which are in a state of dynamic equilibrium. These are the Angiotensin II-Angiotensin 1 Receptor axis and the Angiotensin 1-7-Mas receptor axis as illustrated in Fig. 3a. The former causes an inflammatory response and vasoconstriction while the latter suppresses inflammatory responses and supports vasodilation [45]. Disruption of the equilibrium between these two axes disturbs the homeostasis maintained by RAAS thus regulating systemic inflammation.

As already discussed, sars cov2 gains entry into the host lungs via ACE2 receptor binding, thus rendering the receptor unavailable for maintenance of RAAS. An imbalance between the two axes of RAAS results in a shift in equilibrium towards the pro-inflammatory pathway mediated by Angiotensin 1 receptor axis, as depicted in Fig. 3b [46]. Many studies have also reported increased levels of angiotensin II in covid 19 patients when compared to healthy individuals, and is found to be in linear association with viral load and lung injury [47]. Also, angiotensin
Fig. 3 a In healthy state, the Angiotensin II-Angiotensin 1 Receptor axis and the Angiotensin 1-7-Mas receptor axis are in a state of dynamic equilibrium to maintain the blood pressure. The former causes an inflammatory response while the latter suppresses inflammatory responses. b In SARS-CoV-2 infected state, viral binding to ACE2 renders it unavailable to bind to Angiotensin II causing an imbalance between the two axes and a shift towards the proinflammatory functions
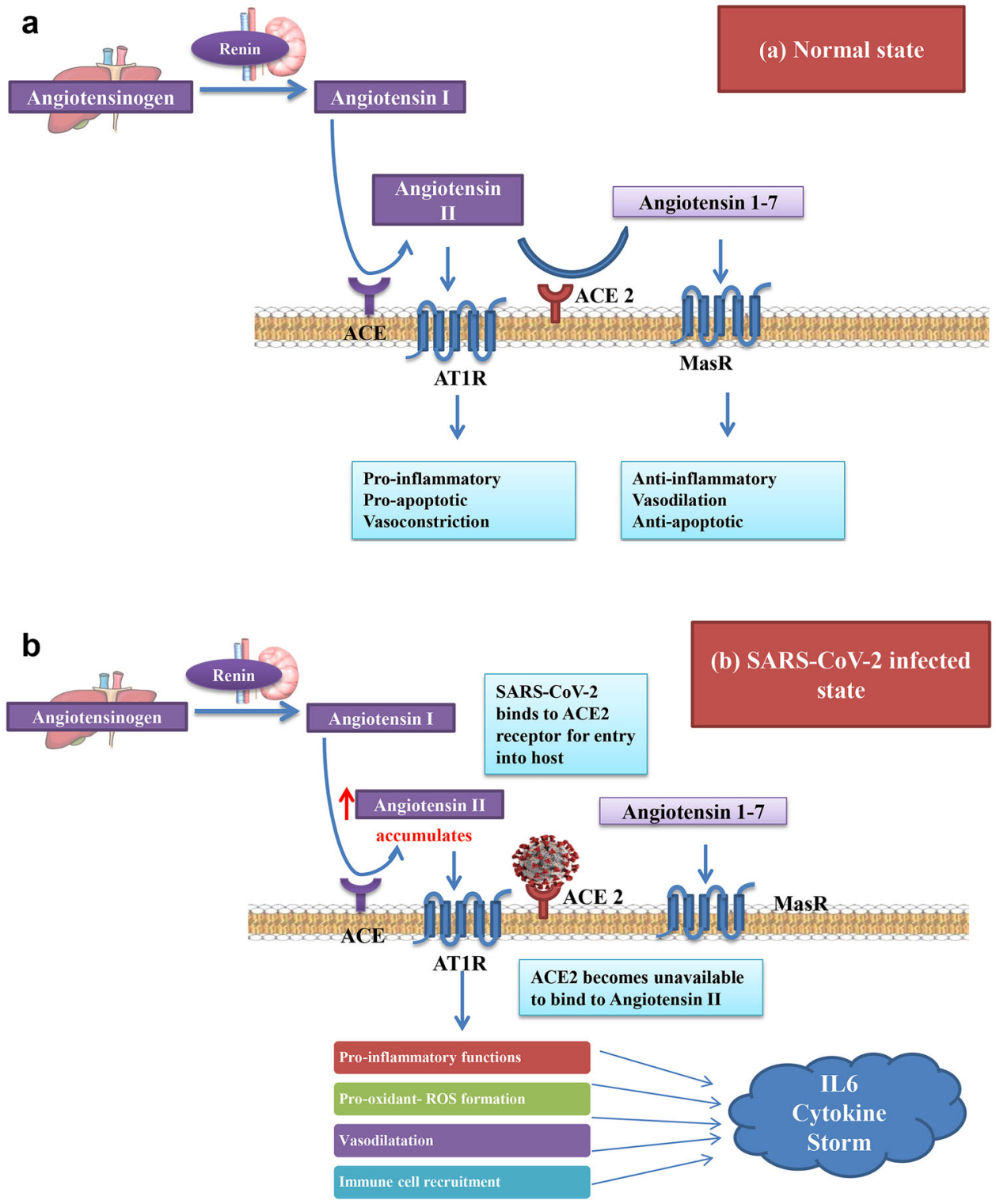
II is known to significantly increase the expression of IL-6 mRNA and protein in a dose-dependent manner [48].

Angiotensin II binds to angiotensin I receptor which then initiates a downstream signaling that leads to oxidative stress, formation of reactive oxygen species (ROS) and upregulated expression of IL-6 [49]. Conversely, IL-6 released by macrophages promotes enhanced expression of Angiotensin 1 receptor, which attaches itself to walls of endothelial cells leading to cell and vascular inflammation [50]. This, in turn, creates a redox imbalance, causing an increase in oxidative burden and IL- 6 expression. Hence, IL-6 and Angiotensin II activate each other by exerting a positive feedback control. Treatment of COVID-19 patients with RAAS inhibitors such as ACE inhibitors (ACEIs) and angiotensin II type 1 receptor blockers (ARBs) led to attenuation of the inflammatory response, as observed through the inhibition of IL-6 levels, increased $\mathrm{CD} 3$ and CD8 $\mathrm{T}$ cell counts in peripheral blood and decreased viral load $[46,51]$.

\section{IL-6: Predictor of Disease Prognosis and Associated Risk Factors in COVID-19 Patients}

Elevated IL-6 serum levels are linked to poorer prognosis and deteriorating clinical outcomes in COVID-19 patients. It has been indicated that moderately elevated levels of IL6 above $80 \mathrm{pg} / \mathrm{ml}$ were adequate to identify COVID-19 patients with a high risk of respiratory failure [23]. Furthermore, RNAaemia (SARS CoV2 nucleic acid) in serum was strongly associated with cytokine storm and an immensely high IL-6 serum levels [52]. Old age, high SOFA score (Sequential Organ Failure Assessment), high BMI, elevated D-dimers and high IL-6 levels were proven risk factors for increase in mortality \& poor prognosis in adult patients [53]. A retrospective study conducted on ICU patients revealed significantly high levels of IL-6 in nonsurvivor group compared to survivor with AUROC of 0.73 [54]. Another, two hospital based retrospective study also revealed higher baseline IL-6 levels in severe cases [55]. A study generated two predictive models based on high flow oxygen requirement which also demonstrated that patients with higher IL-6 values are early identification markers of COVID-19 severity [56]. It was also significantly related with elevated levels of AST, ALT and GGT during hospitalization of COVID-19 patients [57]. Higher IL-6 levels has also been linked to long term care need in elderly patients and in-hospital mortality rates [61]. A study conducted on 225 COVID-19 patients in Southwest quaternary United states hospital found that elevated levels of IL-6 positively correlates with adverse cardiac events or deaths [58].
Among the predisposing conditions, diabetes emerged as the most important association in COVID-19 patients with mortality rate of $16-35 \%$ [59]. Recent data from COVID-19 patients with diabetes have shown elevated levels of systemic IL-6 compared to patients without diabetes [60]. SARS-CoV-2 infection may exacerbate preexisting diabetes, as ACE2 expression in pancreatic cells contributes to impaired insulin secretion as well as insulin resistance [61]. Thus, IL-6 may govern COVID-19 disease severity in diabetics. Similarly, obese patients with COVID-19 are more likely to develop severe respiratory distress syndrome [62]. They have higher concentration of pro-inflammatory cytokines both in steady state and in diseases [63]. Further, obese patients tend to have heightened IL-6 production in adipocytes leading to decreased anti-viral immune response by neutrophils and hence, uncontrolled viral replication at early stages of infection [63]. Age is another risk factor for poorer prognosis in COVID-19 [53]. This age-associated vulnerability is probably due to increased expression of ACE2 with age accounting for higher mortality in elderly patients [64].

Smoking has also been identified as a risk factor for SARS-CoV-2 infection. It has already been stated that active smokers are more susceptible to influenza virus infections and are more likely to develop chronic obstructive pulmonary disease (COPD) [65]. They have increased ACE2 expression in the lungs, which may potentially explain a fourfold increased risk of development of severe COVID-19 in smokers [66, 67]. During evaluation of risk factors associated with COVID-19 in a Chinese cohort, it was found that $19.2 \%$ of patients were smokers [68].

COVID-19 mortality rates in males are twice that of females [69]. Similar data on association of male gender with poorer prognosis were obtained earlier for SARS-CoV and MERS-CoV infections [70, 71]. The reason behind this gender difference lies in the ACE2 gene which is an $\mathrm{X}$-linked gene. During X-chromosome inactivation, a significant number of genes undergo dosage compensation. However, ACE2, escapes X chromosome inactivation, thus contributing to gender disparity in disease susceptibility [72]. Endocrine factors may further contribute to gender disparity in immune responses [73, 74]. Viral load in COVID-19 females is lower in comparison to males, with concomitant higher $\mathrm{CD}^{+}{ }^{+} \mathrm{T}$ cells [79]. A comparative analysis depicted that course of COVID-19 is more severe in males. The number of men who died from COVID-19 is 2.4 times that of females $(70.3 \%$ vs. $29.7 \%)$. This suggested that male patients are at increased risk of worse outcomes and death compared to female patients, independent of age [75]. A study also concluded that levels of IL-6 were significantly elevated in males compared to females. Also, a higher number of males were reported to 
experience lymphopenia [76]. Therefore, immune-modulatory effects of hormones such as estrogens contribute to decrease susceptibility and better prognosis in women infected with SARS-CoV-2.

\section{Anti-IL-6 Agents: Therapeutic Targets for COVID-19 Infection}

A diverse spectrum of pharmaceutical agents is presently being employed for the treatment and management of COVID-19 infection. Monoclonal antibody Tocilizumab an IL-6 receptor antibody has been advocated for treatment [77-79].

While antivirals like remdesivir specifically target the viral replication by inhibiting the RNA-dependant-RNA polymerase [80], other drugs like Hydroxychloroquine inhibit the CS but have adverse effects like gastrointestinal complications, retinopathy and QT interval prolongation in treated COVID-19 patients [81]. Thus, in addition to antiviral drugs, ameliorating the CS would prove to be an efficient treatment strategy to successfully combat the disease.

Plant-derived natural immunosuppressant compounds, such as curcumin, luteolin, piperine, resveratrol, allicin, colchicines, eugenol etc. have been known to inhibit the pro-inflammatory cytokines and chemokines. This specific targeting of cytokines is achieved by the inhibitory action on specific signalling cascades like NF-KB, JAK/STAT, MAPK/ERK [82]. Use of these plants sources with enhanced bioavailability and safety profiles is a ray of hope and opens up a novel approach to mitigate the CS in COVID-19.

The latest treatment molecules for combating the CS have been the monoclonal antibodies (MoAbs) emerging as the versatile class of biotherapeutics for passive immunotherapy. The use of monoclonal antibodies against viral infections like influenza and rheumatoid arthritis have already shown promising results [83]. Since IL-6 is found to be significantly upregulated in COVID-19 infection, MoAbs that can neutralize its effects may serve as a potential treatment option as depicted in Fig. 2.

Tocilizumab is a recombinant humanised monoclonal antibody of the IgG1 class, which is directed against both the soluble and membrane-bound forms of the interleukin6 (IL-6) receptor.

Small retrospective cohort studies on patients affected by severe COVID-19 demonstrated that treatment with Tocilizumab improved the clinical profile of COVID-19 patients [84]. Patients with severe respiratory failure displaying macrophage activation syndrome (MAS) showed decreased expression of human leucocyte antigen-D (HLADR) which was mediated by IL-6 expression. Treatment of these patients with Tocilizumab partially restored HLA-DR expression [85]. A case study of 64 year old male treated with tocilizumab for hemophagocytic lymphohistocytosis syndrome and COVID-19 has also shown decreased levels of inflammatory markers including IL-6 [86]. Tocilizumab has been recommended for use in severe or critically ill patients with confirmed elevated levels of IL-6 in the "Diagnosis and Treatment Protocol for Novel Coronavirus Pneumonia (Trial Version 7)" issued by the National Health Commission of China [87]. Several clinical trials on the use of Tocilizumab have been attempted in different COVID-19 population groups ranging from patients with pneumonia to life-threatening CS associated condition (available on ClinicalTrials.gov.in).

Sarilumab, a human MoAb against IL-6 receptor, is presently in use for the treatment of RA patients [88]. Addition of Sarilumab in the treatment regimen of eight patients diagnosed positive for SARS-CoV-2 was done and a significant improvement in respiratory function $(30 \%$ reduction in oxygen requirement compared to baseline) was observed leading to an early discharge, merely 14 days after hospital admission to hospital [89].

Siltuximab, an anti-IL-6 antibody, has been evaluated in the Siltuximab in Severe COVID-19 (SISCO) study. Mortality rates were compared in two cohorts consisting of patients on treatment regimen with or without siltuximab and it was found that siltuximab receiving patients exhibited a decreased mortality rate. Another anti- IL-6 MoAb which is presently suggested as an effective treatment option for RA and psoriatic arthritis is Clazakizumab [90, 91]. Significant improvement has been observed in respiratory functions, inflammatory markers and oxygen requirements in COVID-19 patients with significantly raised levels of CRP and IL-6 after treatment with Clazakizumab [92].

The effects of cytokines involved in COVID-19 induced CS are mediated via the JAK/STAT cascade as illustrated in Fig. 2. Thus, CS in SARS-CoV-2 can also be alleviated using JAK inhibitors (JAKi). Ruxolitinib is the first FDA approved JAK inhibitor that inhibits both JAK1 and 2 [93]. It was observed that patients who received Ruxolitinib had a faster clinical and chest CT improvement and displayed significantly decreased levels of cytokines compared to control group. Moreover, no deaths were recorded in the Ruxolitinib receiving group $(\mathrm{n}=20)$ while three patients died due to respiratory failure in the control group $(\mathrm{n}=21)$ [94]. Another JAKi, Baricitinib has been suggested to be of therapeutic use against SARS-CoV-2 [95]. Baricitinibtreated COVID-19 patients achieve greater improvements in all clinical characteristics (fever, cough and dyspnea) and respiratory function parameters compared to baseline. A substantial number of trials on anti-IL6 agents that have 
been presently undertaken will pave the path for treatment strategies in the days to come.

\section{Conclusion and Future Perspectives}

In conclusion, the role of IL-6 in the immunopathology of COVID-19 is pivotal. IL-6 occupies the centre stage in initiating and potentiating the dreaded CS. It also helps in predicting disease severity \& mortality in COVID-19. Raised IL-6 levels were associated with ARDS, increased requirement of mechanical ventilation, prolonged hospital stay, worse SOFA score, multiple organ impairment and intensive care unit admission. This review elaborated IL-6 levels in preference to other cytokines raised in cytokine storm because anti IL-6 antibodies and IL-6 receptor inhibitors have already been in vogue for the treatment of autoimmune diseases and now have been repurposed for the treatment of COVID-19 with some success. In addition, JAK inhibitors are also being tried in clinical trials for the treatment of COVID-19.

Molecules that block ADAM 10 hold a lot of promise since they tilt the inflammatory balance from pro-inflammatory to anti-inflammatory pathway thus abetting the cytokine storm which is the main pathological event that propels SARS-COVID-19 patients into a downhill course. Further studies on genetic polymorphisms in various ethnic groups which affect IL-6 levels need to be conducted for stratification of COVID patients into mild, moderate and severe. Delineating such genetic polymorphisms may also pave the path for pharmacogenomic database for the exhibition of anti-IL-6 antibodies.

Author contributions JS: Data acquisition, original draft, Editing. KG: Data creation, resources, writing, original draft. SG: Review and editing, data creation. PP: Review and editing. MR: Review and editing. PM: Review and editing. MG: Data creation, review and editing. SM: Supervision. PS: Review and editing, supervision. MB: Conceptualization, supervision, review and editing.

Funding This review article did not receive any specific grant from funding agencies in the public, commercial sectors.

\section{Declarations}

Conflict of interest The authors declare that they have no conflict of interest to disclose.

\section{References}

1. WHO Pneumonia of unknown cause - China [Internet]. WHO. World Health Organization; [cited 2020 Aug 14]. http://www. who.int/csr/don/05-january-2020-pneumonia-of-unkown-causechina/en/.
2. COVID-19 Public Health Emergency of International Concern (PHEIC) Global research and innovation forum [Internet]. [cited 2020]. https://www.who.int/publications/m/item/covid-19-publichealth-emergency-of-international-concern-(pheic)-globalresearch-and-innovation-forum.

3. de Wit E, van Doremalen N, Falzarano D, Munster VJ. SARS and MERS: recent insights into emerging coronaviruses. Nat Rev Microbiol. 2016;14(8):523-34.

4. Li X, Geng M, Peng Y, Meng L, Lu S. Molecular immune pathogenesis and diagnosis of COVID-19. J Pharm Anal. 2020;10(2):102-8.

5. Lu L, Zhong W, Bian Z, Li Z, Zhang K, Liang B, et al. A comparison of mortality-related risk factors of COVID-19, SARS, and MERS: a systematic review and meta-analysis. J Infect. 2020;81(4):e18-25.

6. Zhou P, Yang X-L, Wang X-G, Hu B, Zhang L, Zhang W, et al. A pneumonia outbreak associated with a new coronavirus of probable bat origin. Nature. 2020;579(7798):270-3.

7. Valencia DN. Brief review on COVID-19: the 2020 pandemic caused by SARS-CoV-2. Cureus [Internet]. 2020. https://doi.org/ 10.7759/cureus.7386.

8. Huang C, Wang Y, Li X, Ren L, Zhao J, Hu Y, et al. Clinical features of patients infected with 2019 novel coronavirus in Wuhan China. Lancet. 2020;395(10223):497-506.

9. Lan J, Ge J, Yu J, Shan S, Zhou H, Fan S, et al. Structure of the SARS-CoV-2 spike receptor-binding domain bound to the ACE2 receptor. Nature. 2020;581(7807):215-20.

10. Ou X, Liu Y, Lei X, Li P, Mi D, Ren L, et al. Characterization of spike glycoprotein of SARS-CoV-2 on virus entry and its immune cross-reactivity with SARS-CoV. Nat Commun. 2020;11(1): 1620 .

11. Hamming I, Timens W, Bulthuis M, Lely A, Navis G, van Goor $\mathrm{H}$. Tissue distribution of ACE2 protein, the functional receptor for SARS coronavirus. a first step in understanding SARS pathogenesis. J Pathol. 2004;203(2):631-7.

12. Lukassen S, Chua RL, Trefzer T, Kahn NC, Schneider MA, Muley T, et al. SARS -CoV-2 receptor ACE 2 and TMPRSS 2 are primarily expressed in bronchial transient secretory cells. EMBO J. 2020. https://doi.org/10.15252/embj.20105114.

13. Cheng Y, Luo R, Wang K, Zhang M, Wang Z, Dong L, et al. Kidney impairment is associated with in-hospital death of COVID-19 patients [Internet]. Nephrology. 2020. https://doi.org/ 10.1101/2020.02.18.20023242.

14. Robba C, Battaglini D, Pelosi P, Rocco PRM. Multiple organ dysfunction in SARS-CoV-2: MODS-CoV-2. Expert Rev Respir Med. 2020;22:1-4.

15. Hoffmann M, Kleine-Weber H, Schroeder S, Krüger N, Herrler $\mathrm{T}$, Erichsen S, et al. SARS-CoV-2 cell entry depends on ACE2 and TMPRSS2 and Is blocked by a clinically proven protease inhibitor. Cell. 2020;181(2):271-280.e8.

16. Muniyappa R, Gubbi S. COVID-19 pandemic, coronaviruses, and diabetes mellitus. Am J Physiol-Endocrinol Metab. 2020;318(5):E736-41.

17. Gubernatorova EO, Gorshkova EA, Polinova AI, Drutskaya MS. IL-6: relevance for immunopathology of SARS-CoV-2. Cytokine Growth Factor Rev. 2020;53:13-24.

18. Moore JB, June $\mathrm{CH}$. Cytokine release syndrome in severe COVID-19. Science. 2020;368(6490):473-4.

19. Shimabukuro-Vornhagen A, Gödel P, Subklewe M, Stemmler HJ, Schlößer HA, Schlaak M, et al. Cytokine release syndrome. J immuno cancer. 2018;6(1):56.

20. Shimizu M. Clinical features of cytokine storm syndrome. In: Cron RQ, Behrens EM, editors. Cytokine storm syndrome. Cham: Springer International Publishing; 2019. p. 31-41. https://doi.org/ 10.1007/978-3-030-22094-5_3. 
21. Du F, Liu B, Zhang S. COVID-19: the role of excessive cytokine release and potential ACE2 down-regulation in promoting hypercoagulable state associated with severe illness. J Thromb Thrombolysis. 2020. https://doi.org/10.1007/s11239-020-022242.

22. Picchianti Diamanti A, Rosado MM, Pioli C, Sesti G, Laganà B. Cytokine release syndrome in COVID-19 patients, a new scenario for an old concern: the fragile balance between infections and autoimmunity. IJMS. 2020;21(9):3330.

23. Herold T, Jurinovic V, Arnreich C, Lipworth BJ, Hellmuth JC, von Bergwelt-Baildon M, et al. Elevated levels of IL-6 and CRP predict the need for mechanical ventilation in COVID-19. J Allergy Clin Immunol. 2020;146(1):128-136.e4.

24. Rose-John S. Interleukin-6 biology is coordinated by membranebound and soluble receptors: role in inflammation and cancer. J Leukoc Biol. 2006;80(2):227-36.

25. Böttcher JP, Schanz O, Garbers C, Zaremba A, Hegenbarth S, Kurts C, et al. IL-6 trans-signaling-dependent rapid development of cytotoxic CD8+ T cell function. Cell Rep. 2014;8(5):1318-27.

26. Cox MA, Kahan SM, Zajac AJ. Anti-viral CD8 T cells and the cytokines that they love. Virology. 2013;435(1):157-69.

27. Evans SS, Repasky EA, Fisher DT. Fever and the thermal regulation of immunity: the immune system feels the heat. Nat Rev Immunol. 2015;15(6):335-49.

28. Pyle CJ, Uwadiae FI, Swieboda DP, Harker JA. Early IL-6 signalling promotes IL-27 dependent maturation of regulatory $\mathrm{T}$ cells in the lungs and resolution of viral immunopathology. PLoS Pathog. 2017;13(9):e1006640.

29. Yang M-L, Wang C-T, Yang S-J, Leu C-H, Chen S-H, Wu C-L, et al. IL-6 ameliorates acute lung injury in influenza virus infection. Sci Rep. 2017;7(1):43829.

30. Lauder SN, Jones E, Smart K, Bloom A, Williams AS, Hindley JP, et al. Interleukin-6 limits influenza-induced inflammation and protects against fatal lung pathology: immunity to infection. Eur $\mathbf{J}$ Immunol. 2013;43(10):2613-25.

31. Velazquez-Salinas L, Verdugo-Rodriguez A, Rodriguez LL, Borca MV. The role of interleukin 6 during viral infections. Front Microbiol. 2019;10(10):1057.

32. Dienz O, Rincon M. The effects of IL-6 on CD4 T cell responses. Clin Immunol. 2009;130(1):27-33.

33. Hou W, Kang HS, Kim BS. Th17 cells enhance viral persistence and inhibit $\mathrm{T}$ cell cytotoxicity in a model of chronic virus infection. J Exp Med. 2009;206(2):313-28.

34. Barnes BJ, Adrover JM, Baxter-Stoltzfus A, Borczuk A, CoolsLartigue J, Crawford JM, et al. Targeting potential drivers of COVID-19: neutrophil extracellular traps. J Exp Med. 2020;217(6):e20200652.

35. Wu W, Dietze KK, Gibbert K, Lang KS, Trilling M, Yan H, et al. TLR ligand induced IL-6 counter-regulates the anti-viral CD8+ $\mathrm{T}$ cell response during an acute retrovirus infection. Sci Rep. 2015;5(1):10501.

36. Indalao IL, Sawabuchi T, Takahashi E, Kido H. IL-1 $\beta$ is a key cytokine that induces trypsin upregulation in the influenza viruscytokine-trypsin cycle. Arch Virol. 2017;162(1):201-11.

37. Schumacher R-J. ADAM17 activity and IL-6 trans-signaling in inflammation and cancer. Cancers. 2019;11(11):1736.

38. Chalaris A, Garbers C, Rabe B, Rose-John S, Scheller J. The soluble Interleukin 6 receptor: generation and role in inflammation and cancer. Eur J Cell Biol. 2011;90(6-7):484-94.

39. Rose-John S. IL-6 trans-signaling via the soluble IL-6 receptor: importance for the pro-inflammatory activities of IL-6. Int J Biol Sci. 2012;8(9):1237-47.

40. Tenhumberg S, Waetzig GH, Chalaris A, Rabe B, Seegert D, Scheller J, et al. Structure-guided optimization of the interleukin6 trans-signaling antagonist sgp130. J Biol Chem. 2008;283(40):27200-7.
41. Jostock T, Müllberg J, Özbek S, Atreya R, Blinn G, Voltz N, et al. Soluble gp130 is the natural inhibitor of soluble interleukin6 receptor transsignaling responses: soluble gp130 inhibits transsignaling responses. Eur J Biochem. 2001;268(1):160-7.

42. Schett G. Physiological effects of modulating the interleukin-6 axis. Rheumatology. 2018;57(suppl_2):ii43-50.

43. Furuya Y, Satoh T, Kuwana M. Interleukin-6 as a potential therapeutic target for pulmonary arterial hypertension. Int $\mathbf{J}$ Rheumatol. 2010;2010:1-8.

44. Zheng Y-Y, Ma Y-T, Zhang J-Y, Xie X. COVID-19 and the cardiovascular system. Nat Rev Cardiol. 2020;17(5):259-60.

45. Hampl V, Herget J, Bíbová J, Baňasová A, Husková Z, Vaňourková $Z$, et al. Intrapulmonary activation of the angiotensin-converting enzyme type 2/angiotensin 1-7/G-proteincoupled mas receptor axis attenuates pulmonary hypertension in Ren-2 transgenic rats exposed to chronic hypoxia. Physiol Res. 2015;27:25-38.

46. Meng J, Xiao G, Zhang J, He X, Ou M, Bi J, et al. Reninangiotensin system inhibitors improve the clinical outcomes of COVID-19 patients with hypertension. Emerg Microb Infect. 2020;9(1):757-60.

47. Liu Y, Yang Y, Zhang C, Huang F, Wang F, Yuan J, et al. Clinical and biochemical indexes from 2019-nCoV infected patients linked to viral loads and lung injury. Sci China Life Sci. 2020;63(3):364-74.

48. Funakoshi Y, Ichiki T, Ito K, Takeshita A. Induction of interleukin-6 expression by angiotensin II in rat vascular smooth muscle cells. Hypertension. 1999;34(1):118-25.

49. Gomolak JR, Didion SP. Angiotensin II-induced endothelial dysfunction is temporally linked with increases in interleukin-6 and vascular macrophage accumulation. Front Physiol. 2014. https://doi.org/10.3389/fphys.2014.00396/abstract.

50. Liu PP, Blet A, Smyth D, Li H. The science underlying COVID19: implications for the cardiovascular system. Circulation. 2020;142(1):68-78.

51. Yang G, Tan Z, Zhou L, Yang M, Peng L, Liu J, et al. Angiotensin II receptor blockers and angiotensin-converting enzyme inhibitors usage is associated with improved inflammatory status and clinical outcomes in COVID-19 patients with hypertension [Internet]. Infect Dis (Except HIV/AIDS). 2020. https://doi.org/ 10.1101/2020.03.31.20038935.

52. Chen X, Zhao B, Qu Y, Chen Y, Xiong J, Feng Y, et al. Detectable serum severe acute respiratory syndrome coronavirus 2 viral load (RNAemia) is closely correlated with drastically elevated interleukin 6 level in critically Ill patients with coronavirus disease 2019. Clin Infect Dis. 2020;71:449.

53. Zhou F, Yu T, Du R, Fan G, Liu Y, Liu Z, et al. Clinical course and risk factors for mortality of adult inpatients with COVID-19 in Wuhan, China: a retrospective cohort study. Lancet. 2020;395(10229):1054-62.

54. Gorham J, Moreau A, Corazza F, Peluso L, Ponthieux F, Talamonti M, et al. Interleukine-6 in critically ill COVID-19 patients: a retrospective analysis. PLOS ONE. 2020;15(12):e0244628.

55. Zhu W, Wu Y, Liu Y, Li B, Xiong P, Cui D, et al. Baseline interleukin-6 level predicts risk of severe COVID-19: a twocenter, retrospective study [Internet]. In Review; 2020 Nov [cited 2021 Jan 11]. https://www.researchsquare.com/article/rs-68501/ v1.

56. Riveiro-Barciela M, Labrador-Horrillo M, Camps-Relats L, González-Sans D, Ventura-Cots M, Terrones-Peinador M, et al. Simple predictive models identify patients with COVID-19 pneumonia and poor prognosis. PLOS ONE. 2020;15(12):e0244627.

57. Xiang D, Ren X, Chen Q, Yu H, Li X, Liu D. Association of ACEI/ARB, inflammatory cytokines, and antiviral drugs with 
liver dysfunction in patients with hypertension and COVID-19. Clin Exp Hyper. 2020;1-6.

58. Nicholas Nguyen, Hao Nguyen, Chirag Patel, Farukh Ikram, Priyanka Acharya, Anmol Dhillion, et al. (2020) Abstract 17279: elevated interleukin-6 levels in COVID-19-infected patients are associated with major adverse cardiac events and/or mortality. Circulation. 2020;142(Suppl_3):A17279-A17279.

59. Guo W, Li M, Dong Y, Zhou H, Zhang Z, Tian C, et al. Diabetes is a risk factor for the progression and prognosis of COVID-19. Diabetes Metab Res Rev. 2020, e3319.

60. Zhu L, She Z-G, Cheng X, Qin J-J, Zhang X-J, Cai J, et al. Association of blood glucose control and outcomes in patients with COVID-19 and pre-existing type 2 diabetes. Cell Metab. 2020;31(6):1068-1077.e3.

61. Bindom SM, Lazartigues E. The sweeter side of ACE2: physiological evidence for a role in diabetes. Mol Cell Endocrinol. 2009;302(2):193-202.

62. Banerjee M, Gupta S, Sharma P, Shekhawat J, Gauba K. Obesity and COVID-19: a fatal alliance. Ind J Clin Biochem. 2020;35(4):410-7.

63. Richard C, Wadowski M, Goruk S, Cameron L, Sharma AM, Field CJ. Individuals with obesity and type 2 diabetes have additional immune dysfunction compared with obese individuals who are metabolically healthy. BMJ Open Diab Res Care. 2017;5(1):e000379.

64. Baker SA, Kowk S, Berry GJ, Montine TJ. Angiotensin-converting enzyme 2 (ACE2) expression increases with age in patients requiring mechanical ventilation [Internet]. Pathology. 2020. https://doi.org/10.1101/2020.07.05.20140467.

65. Lawrence H, Hunter A, Murray R, Lim WS, McKeever T. Cigarette smoking and the occurrence of influenza: systematic review. J Infect. 2019;79(5):401-6.

66. Leung JM, Yang CX, Tam A, Shaipanich T, Hackett T-L, Singhera GK, et al. ACE-2 expression in the small airway epithelia of smokers and COPD patients: implications for COVID-19. Eur Respir J. 2020;55(5):2000688.

67. Brake SJ, Barnsley K, Lu W, McAlinden KD, Eapen MS, Sohal SS. Smoking upregulates angiotensin-converting enzyme-2 receptor: a potential adhesion site for novel coronavirus SARSCoV-2 (Covid-19). JCM. 2020;9(3):841.

68. Zhao Q, Meng M, Kumar R, Wu Y, Huang J, Lian N, et al. The impact of COPD and smoking history on the severity of COVID19: a systemic review and meta-analysis. J Med Virol. 2020;92(10):1915-21.

69. Wu Z, McGoogan JM. Characteristics of and important lessons from the coronavirus disease 2019 (COVID-19) outbreak in China: summary of a report of 72314 cases from the chinese center for disease control and prevention. JAMA. 2020;323(13):1239.

70. Karlberg J. Do men have a higher case fatality rate of severe acute respiratory syndrome than women do? Am J Epidemiol. 2004;159(3):229-31.

71. Badawi A, Ryoo SG. Prevalence of comorbidities in the Middle East respiratory syndrome coronavirus (MERS-CoV): a systematic review and meta-analysis. Int J Infect Dis. 2016;49:129-33.

72. Burrell LM, Harrap SB, Velkoska E, Patel SK. The ACE2 gene: its potential as a functional candidate for cardiovascular disease. Clin Sci. 2013;124(2):65-76.

73. Klein SL, Flanagan KL. Sex differences in immune responses. Nat Rev Immunol. 2016;16(10):626-38.

74. La Vignera S, Cannarella R, Condorelli RA, Torre F, Aversa A, Calogero AE. Sex-specific SARS-CoV-2 mortality: among hormone-modulated ACE2 expression, risk of venous thromboembolism and hypovitaminosis D. IJMS. 2020;21(8):2948.
75. Jin J-M, Bai P, He W, Wu F, Liu X-F, Han D-M, et al. Gender differences in patients with COVID-19: focus on severity and mortality. Front Public Health. 2020;29(8):152.

76. Lv Z, Cheng S, Le J, Huang J, Feng L, Zhang B, et al. Clinical characteristics and co-infections of 354 hospitalized patients with COVID-19 in Wuhan, China: a retrospective cohort study. Microb Infect. 2020;22(4-5):195-9.

77. Antiviral Therapy [Internet]. COVID-19 treatment guidelines. [cited 2021 Jun 3]. https://www.covid19treatmentguidelines.nih. gov/antiviral-therapy/.

78. Sethi A, Bach H. Evaluation of current therapies for COVID-19 treatment. Microorganisms. 2020;8(8):1097.

79. Tobaiqy M, Qashqary M, Al-Dahery S, Mujallad A, Hershan AA, Kamal MA, et al. Therapeutic management of patients with COVID-19: a systematic review. Infect Prev Pr. 2020;2(3):100061.

80. Kokic G, Hillen HS, Tegunov D, Dienemann C, Seitz F, Schmitzova J, et al. Mechanism of SARS-CoV-2 polymerase stalling by remdesivir. Nat Commun. 2021;12(1):279.

81. Satarker S, Ahuja T, Banerjee M, Balaji EV, Dogra S, Agarwal T, et al. Hydroxychloroquine in COVID-19: potential mechanism of action against SARS-CoV-2. Curr Pharmacol Rep. 2020;6(5):203-11.

82. Peter AE, Sandeep BV, Rao BG, Kalpana VL. Calming the storm: natural immunosuppressants as adjuvants to target the cytokine storm in COVID-19. Front Pharmacol. 2021;11:583777.

83. Perspectives on monoclonal antibody therapy as potential therapeutic intervention for Coronavirus disease-19 (COVID-19). Asian Pac J Allergy Immunol [Internet]. 2020 [cited 2020 May 26]. http://apjai-journal.org/wp-content/uploads/2020/03/2.pdf.

84. Xu X, Han M, Li T, Sun W, Wang D, Fu B, et al. Effective treatment of severe COVID-19 patients with tocilizumab. Proc Natl Acad Sci USA. 2020;117(20):10970-5.

85. Giamarellos-Bourboulis EJ, Netea MG, Rovina N, Akinosoglou $\mathrm{K}$, Antoniadou A, Antonakos N, et al. Complex immune dysregulation in COVID-19 patients with severe respiratory failure. Cell Host Microbe. 2020. https://doi.org/10.1016/j.chom.2020.04. 009.

86. Eroglu A, Kartal S, Saral OB. Helmet mask and tocilizumab for a patient with hemophagocytic lymphohistiocytosis syndrome and COVID-19: a case report. Braz J Anesthesiol (English Edition) [Internet]. 2020 Dec 26 [cited 2021 Jan 11]. http://www.science direct.com/science/article/pii/S0104001420302153.

87. (Released by National Health Commission \& National Administration of Traditional Chinese Medicine on March 3, 2020). Diagnosis and treatment protocol for novel coronavirus pneumonia (Trial Version 7): Chinese Medical Journal. 2020. 133(9):1087-95.

88. Lamb YN, Deeks ED. Sarilumab: a review in moderate to severe rheumatoid arthritis. Drugs. 2018;78(9):929-40.

89. Benucci M, Giannasi G, Cecchini P, Gobbi FL, Damiani A, Grossi V, et al. COVID-19 pneumonia treated with sarilumab: a clinical series of eight patients. J Med Virol. 2020. jmv.26062.

90. Weinblatt ME, Mease P, Mysler E, Takeuchi T, Drescher E, Berman A, et al. The efficacy and safety of subcutaneous clazakizumab in patients with moderate-to-severe rheumatoid arthritis and an inadequate response to methotrexate: results from a multinational, phase IIb, randomized, double-blind, placebo/ active-controlled, dose-Ra: clazakizumab in moderate-to-severe Ra. Arthritis Rheumatol. 2015;67(10):2591-600.

91. Bilal J, Riaz IB, Kamal MU, Elyan M, Sudano D, Khan MA. A Systematic review and meta-analysis of efficacy and safety of novel interleukin inhibitors in the management of psoriatic arthritis. JCR: J Clin Rheumatol. 2018;24(1):6-13.

92. Vaidya G, Czer LSC, Kobashigawa J, Kittleson M, Patel J, Chang D, et al. Successful Treatment of severe COVID-19 pneumonia 
with clazakizumab in a heart transplant recipient: a case report. transplantation proceedings. 2020. S0041134520325756.

93. Bjørn ME, Hasselbalch HC. The impact of ruxolitinib treatment on inflammation-mediated comorbidities in myelofibrosis and related neoplasms. Clin Case Rep. 2015;3(6):499-503.

94. Cao Y, Wei J, Zou L, Jiang T, Wang G, Chen L, et al. Ruxolitinib in treatment of severe coronavirus disease 2019 (COVID-19): A multicenter, single-blind, randomized controlled trial. J Allergy Clin Immunol. 2020. https://doi.org/10.1016/j.jaci.2020.05.019.

95. Winthrop KL. The emerging safety profile of JAK inhibitors in rheumatic disease. Nat Rev Rheumatol. 2017;13(4):234-43.

Publisher's Note Springer Nature remains neutral with regard to jurisdictional claims in published maps and institutional affiliations. 